\title{
Um polvorinho de marfim com cenas cinegéticas
}

\section{An ivory powder flask with hunting scenes}

Tiago Rodrigues ${ }^{1}$;

${ }^{1}$ E-mail: tiagorodrigues2@campus.ul.pt Investigador ARTIS-IHA/CH-UL
Resumo: Com este artigo pretende-se estudar um olifante luso-africano realizado na Antiga Serra Leoa no século XVI, que no século seguinte foi transformado em polvorinho. Do olifante em marfim conserva-se um fragmento com $18 \mathrm{~cm}$, enquanto as ferragens que o modificaram medem 7 $\mathrm{cm}$. Esta é uma das raras peças de marfim luso-africano que se encontra disponível no mercado da arte português. Neste artigo pretende-se realçar a estima que estas peças possuíam nos inícios da época moderna na Europa, sobretudo pelas suas associações ao mundo masculino da caça e da montaria áulica. Em comparação com outros exemplos do mesmo género, esta peça apresenta uma decoração segmentada em diferentes zonas. Acena de autorreferência sugere que os artesãos africanos valorizavam o seu trabalho enquanto mestres do marfim, assunto que também pretendemos desenvolver.

Palavras-chaves: Marfim; Polvorinho; Cenas cinegéticas; História da arte

Abstract: With this article we intend to study a luso-africanoliphant carried out in Old Sierra Leone during sixteenth century, which in the following century was transformed into a powder flask.From the Oliphant is preserved a fragment with $18 \mathrm{~cm}$, while the fittings that changed it to powder measure $7 \mathrm{~cm}$. This is one of the rare pieces of Portuguese-African ivory that is available in the Portuguese art market.

With this article we intend to value the esteem that these pieces possessed at the beginning of the modern era in Europe, above all by their associations to the masculine world of the hunting and the aulic mount.In comparison with other examples, this piece features a segmented decoration in different areas.The self-reference scene suggests that African artisans valued their work as masters of ivory, a subject we also intend to develop.

Keywords: Ivory; Powder Flask; Hunting scenes; Art History; 


\section{Introdução}

Os "marfins luso-africano" dizem respeito a talheres, saleiros, olifantes e hostiários, produzidos em três zonas distintas: a Antiga Serra Leoa; a costa do Bakongo, até à foz do rio Congo; a região de Lagos, de Porto Novo e Ajudá, entre o atual Benim e a Nigéria, por artesãos locais, sob encomenda europeia, destinados à Europa.

O conceito luso-africano reivindica a ideia de estarmos perante objetos produzidos por africanos, no continente africano, mas para um consumo luso, como os relatos de Valentim Fernandes, para os anos de 1511, nos permitem justificar (Mark, 2007:189-211). Uma ideia que não está explicita no termo Afro-português, que tem sido usado desde 1959 pela historiografia da arte, pois reforça a ideia de peças africanas produzidas por portugueses.

Repletos de exotismo - um dos principais vetores do colecionismo europeu do século XVI e XVII - estes objetos chegaram à Europa onde foram comercializados e consequentemente preservados nos gabinetes de curiosidades dos príncipes do renascimento.

Utilizadas, estas peças também se fragmentavam, e numa época em que o consumismo não era tão intenso como o do século XXI, com a política do deitar fora pouco vigente, estas fragmentos de exotismo acabavam por adquirir uma nova função e até fisionomia.

Neste artigo pretende-se estudar um desses casos. Trata-se de uma peça que se encontra no mercado de arte, mais propriamente no antiquário AR-PAB | Álvaro Roquette \& Pedro Aguiar Branco, com lojas em Lisboa e Paris, e diz respeito a um curioso e singelo fragmento do que terá sido um olifante sapi-português, produzido pelos artesãos da região da Antiga Serra Leoa, nos inícios do século XVI.

Pretende-se agora realizar uma análise descritiva e comparativa dessa mesma peça de modo a salientar as características que o tornam uma peça tão fundamental no campo dos estudos dos marfins luso-africanos. O facto de estarmos perante o reaproveitamento de um fragmento permite desde já considerar que existiu uma consciência de salvaguarda e preservação da arte dos artesãos africanos que é comprovado pelos cinco polvorinhos sapi-portugueses que chegaram até aos nossos dias, e que estão repartidos entre coleções públicas e privadas.

Por fim, é fundamental deixar explicito o agradecimento ao antiquário AR-PAB, ao Sr. Álvaro Roquette e ao Sr. Pedro Aguiar Branco, assim como a toda a equipa que facultaram um acesso incansável ao objeto em estudo. 


\section{Sobre o marfim e o seu comércio}

A transferência da capital do Império Romano para Constantinopla, no ano de 330 d.C, o aumento da cisão entre as doutrinas católicas e ortodoxa, e o declínio da metade ocidental do Império Romano sob a pressão das tribos germânicas, foram alguns dos principais acontecimentos que contribuíram para o fim da posição do Mar mediterrânico como a grande estrada de intercâmbio comercial e cultural que unia todas as suas costas. Simultaneamente, o Islão alcançou o apogeu muito mais depressa que o ocidental medieval, e é neste seguimento que na Península Ibérica se reconhece a produção islâmica em marfim, sendo Córdova o principal centro de produção.

Serve de exemplo o cofre moçárabe que encontramos na Sé Catedral de Braga, onde convivem os enrolamentos vegetalistas com os caracteres cúficos e as representações humanas, proibidas noutros pontos do Islão. Este tipo de peças acabou por ser apreciado ao longo de toda a Idade Média e terá contribuído para a apreciação do marfim enquanto suporte para a realização de obras de arte, nomeadamente de foro religioso como os dípticos e trípticos produzidos na Île-de-France com cenas da vida de Cristo e da vida da Virgem.

Em correspondência com âmbar e com o coral, o marfim de elefante foi suficientemente valorizado para competir com materiais mais preciosos, de origem inteiramente mineral, como as gemas e os metais nobres. A sua proveniência em terras longínquas, associadas à sua durabilidade e estabilidade bem como o seu caracter exótico -distinguido pela brancura e textura suave - fizeram dele um bem estimado ao longo da história da humanidade que atingiu a dignidade de obra de arte através do trabalho de qualificados artesãos. Um facto que levou a uma caça furtiva, que se intensificou nos últimos dois séculos, através de um comércio e tráfico que ainda hoje perdura, de forma ilegal, e que está a levar à extinção do elefante africano.

Como Jean Massing afirma, para uns África era vista como a terra do ouro, mas para os portugueses do século XV era a terra do marfim. Este "ouro branco" era oriundo quer dos elefantes africanos da savana (Loxodonta africana) como do elefante africano da floresta (Loxodonta africana cyclotis) e os portugueses não só comercializavam a sua matéria-prima em bruto como também estavam interessados em objetos esculpidos por artesãos locais (Massing, 2013).

Influenciados pelos romances de cavalaria e pelo resgestae medieval, os portugueses do 


\section{pontéditora}

século XV compreenderam os seus feitos em África como honrosas ações que haveriam de ser recompensadas através do comercio concretizado com os povos da costa atlântica de África. Concomitantemente, devemos compreender que pela primeira vez na história os portugueses usaram a diplomacia e não a força das armas para ampliar o seu domínio territorial (Pereira, 2010: 26-27).

Deste modo, a participação nas cerimónias de caçada, desempenhou um papel fulcral no incremento das relações sociais entre portugueses e africanos, tendo possibilitado cimentar das relações políticas, sociais e mercantis entre as duas partes.

Ao organizar caçadas aos elefantes, com o auxílio de uma parafernália de armas - lanças, flechas envenenadas e um vasto número de mão-de-obra - os africanos exibiam aos portugueses a sua força e autonomia militar (Pereira, 2010:38).

No ano de 1594, André Alvares de Almada, relata que os africanos matavam os elefantes com azagaias, e os caçadores deslocavam-se a pé ou a cavalo. Por sua vez, os Cassangas, criavam armadilhas e utilizavam venenos. O caçador que encontrava o animal, removia o ferro e cortava a carne. Para o rei iam as quatro patas e a tromba, bem como os dentes com mais de um quintal. Por sua vez a carne era consumida pelos caçadores que levavam os dentes mais leves. Através deste relato concluímos que a começar pelo chefe, toda a comunidade beneficiava da caça, neste caso da carne. Ao participarem nas caçadas os portugueses também beneficiam de partes do animal, como as presas, a cauda, a tromba ou as patas, que lhes eram entregues como presentes diplomáticos.

A primeira referência ao comércio de marfim em bruto data do ano de 1440, e diz respeito a uma entrada na Crónica dos Feitos de Guiné de Gomes Eanes de Zurara. Por este relato tomamos conhecimento que o navegador e escudeiro português, Estevão Afonso, conhecia apenas o comércio do marfim que se fazia através dos portos do levante situados no Mediterrâneo, desconhecendo que este comércio se fazia também pelos portos do império de Marrocos, situados na costa ocidental da África. Ou seja, um homem instruído no comércio e navegação, ignorava que o comércio do marfim se fazia ao longo da costa ocidental, o que testemunha a prioridade do descobrimento da Guiné pelos Portugueses. Situação essa que acabou por se transformar vinte e nove anos depois, em 1469, com todo o marfim da região da Serra Leoa, a pertencer em exclusividade ao rei de Portugal, pelo preço de 1500 reais por quintal.

Entretanto, no ano de 1455, o mercador italiano Antoniotto Usodimare (1416-1462) ao chegar ao rio da Gâmbia, em busca de ouro e malagueta, foi mal recebido por ser confundido com 
inimigos, sendo obrigado a recuar 70 léguas, mas acabou por ser recebido solenemente e presenteado com dentes de elefante, papagaios, escravos e algum almíscar em troca de panos. $\mathrm{O}$ que nos permite considerar que o marfim também trabalhava no quadro da arte de bem receber.

No ano de 1470, Martim Eanes Boa Viagem e o seu irmão Fernão Nunes Boa Viagem passaram a ter o direito ao comércio de marfim proveniente da Guiné. Dois anos depois, em 1472, foi pedido em Cortes que o rei de Portugal autorizasse o livre acesso ao comércio de marfim, e a este pedido o rei respondeu que tudo seria feito para ser proveitoso para o Reino. No ano de 1474 o rei D. Afonso V (1432-1481) concedeu a António Fernandes das Póvoas a mercê de cobrar de Martim Eanes Boa Viagem a quantidade que quisesse de marfim, enquanto este mantivesse o contrato de resgate dessa mercadoria. No ano de 1499 Pedro Álvares de Caminha enviou uma missiva ao rei D. Manuel I (1469-1521) onde pediu novos navios ao rei, pois aqueles de que dispunha estavam para ser reparados no casco aquando da exploração de novos rios, ricos em marfim e escravos. Na mesma carta é referida a troca de escravos por manilhas de marfim e de escravos por marfim a baixo custo (6 manilhas no máximo). Entre 1506 e 1508, Gonçalo Lopes, cavaleiro da Casa Real e almoxarife da Casa dos Escravos, em Lisboa, recebe do rei dinheiro, escravos e mercadorias onde consta relativamente ao marfim, 5 arrobas e 11 arráteis e meio.

Nos diários das viagens do comerciante de tecidos Pieter van den Broecke (1585-1640) (FIG. 1), um dos primeiros europeus a descrever as sociedades da África Ocidental e Central, é referido que no dia a 20 de março de 1606, os portugueses vindos de São Domingos na Guiné chegaram a Portugal com carregamentos de couros, marfim, cera, âmbar e outras mercadorias. Entretanto, a 25 do mesmo mês, navios franceses saíram de Portugal carregados de couros, marfim e âmbar. O que faz de Lisboa um interposto comercial para o marfim chegar ao resto da Europa, nomeadamente aos Países Baixos. Em meados do setembro de 1608, depois de ter negociado no Luango mil setecentos e oitenta e oito dentes de elefante, com um peso de trinta e sete mil e duzentas e treze libras holandesas, o mesmo comerciante partiu do Cabo Branco para a Costa do Ouro. Numa outra referência, datada de 1612 ficamos a saber que o mesmo comerciante partiu de Angola, para a holanda depois de ter negociado cinquenta mil libras holandesas de marfim, no Congo. Esta circulação de marfim, que o comerciante do século XVII nos relata, permite considerar que o marfim circulava na Europa em bruto, e não só em peças talhadas, e que pelo seu valor este era considerado uma matéria fundamental para o comércio do continente africano com a Europa, onde Portugal e principalmente a cidade de 


\section{pontěditora}

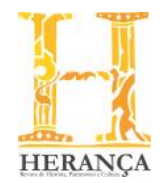

Lisboa tinha um papel central. Era a ela que chegava o marfim em bruto para depois ser escoado para os mercados europeus.

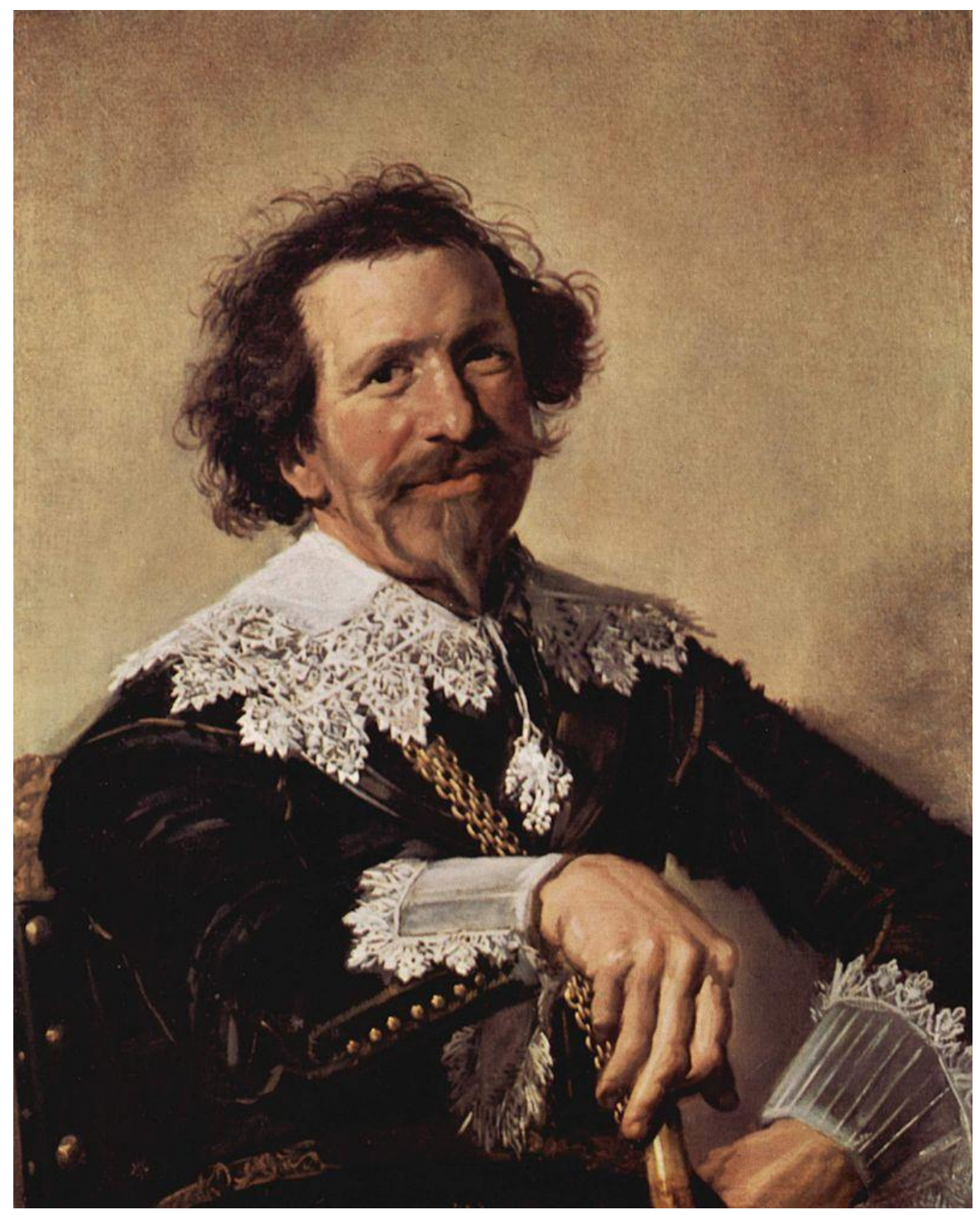

Fig.1. -Retrato de Pieter van den Broecke. Frans Hals. 1633. Kenwood House. Londres. Reino Unido. 


\section{ponteditora}

\section{Esculpir sobre marfim - ateliês e artesãos em África}

É nas fontes contemporâneas à produção destes objetos que conseguimos atestar que estamos perante o trabalho de artesãos africanos, sediados na costa atlântica de África. No entanto não nos permitem atestar o tipo de oficinas, os artesãos e as circunstâncias em que estas peças eram produzidas.

Nessas fontes são mencionadas, na sua maioria, colheres e saleiros de marfim. No manuscrito Esmeraldo do situ Orbius da autoria de Duarte Pacheco Pereira (1460-1533) é referida a produção de colheres de marfim “(...) e nesta terra fazem humas esteiras de palma muito fermosas e asycohares de marfim" (in Carvalho, 1991: 94). O autor refere a produção de delicadas colheres de marfim e realça a habilidade dos artesãos locais, manifestando a sua admiração ao escrever: "nesta terra se fazem os mays sotis collares de marfim e milhorlaurados que em nenhũa parte" (in Carvalho, 1991: 287-288).

Outra fonte importante é os escritos do impressor e tradutor alemão Valentim Fernandes, que desde 1495 se havia estabelecido em Lisboa. Na Descrição da Costa Ocidental de África, redigida entre 1507 e 1510, estão relatadas informações prestadas por Álvaro Velho do Barreiro, um português que viveu durante oito anos na Costa da Guiné. É através dele que são realçadas as competências artística dos artesãos da Antiga Serra Leoa. A aptidão destes homens, a que chama de sapes, no trabalho do metal e do marfim é elogiada e exemplificada no trabalho de colheres, saleiros e manilhas/pulseiras de marfim. Através dos seus relatos ficamos a saber que estes artesãos também podiam produzir por encomenda, pois conseguiam produzir "todallas cousas que lhes mandam fazer".

Pouco mais se sabe sobre a produção destes objetos. Depois encontramos referidos em cartas de quitação, e em inventários. Simultaneamente é nos dado a conhecer o fluxo de chegada destes objetos a Portugal e a sua relativa acessibilidade, mesmo fora dos círculos das elites.

Foi em 1988, que Ezio Bassani enunciou pela primeira vez a existência de um vasto número de oficinas onde identificou vários artesãos que pelas suas qualidades plásticas de execução, apresentavam diferenças significativas na arte de talhe do marfim. Ele percebeu que estava perante um universo onde havia vários artesãos que faziam indiscriminadamente objetos de tipologias diferentes. Na maioria dessas peças está patente uma elevada qualidade plástica, como é o caso do olifante da Armaria Real de Turim (fig.2 e fig. 3). Este, expõe a minucia no esculpir sobre o marfim e evidencia o trabalho de artesão (Bassani, 2000:287), que utilizava o processo descrito pelo artesão do século XII Theopolius (Hendrie, 1847:389). 


\section{pontěditora}

Um processo onde eram utilizados vários cinzeis no trabalho de desbaste do fundo das peças, de maneira a não apresentarem mais de 3 milímetros de espessura. Através do qual era possível reduzir a espessura do fundo de maneira a evidenciar as figuras relevadas. Mas ainda existia uma outra técnica, geralmente utilizada pelos artesãos que melhor dominavam o talhe de marfins -Kerbschnitt. Ou seja, o corte curvo e profundo que permitia escavar um espaço oblíquo, por trás da figura, de modo a sugerir menor espessura. A partir da presa de elefante o artesão tinha como prioridade produzir as peças de maior dimensão - olifantes, saleiros e hostiários. Com a restante matéria-prima da mesma presa eram esculpidos talheres (colheres, garfos e cabos de adagas) e olifantes de reduzidas dimensões.

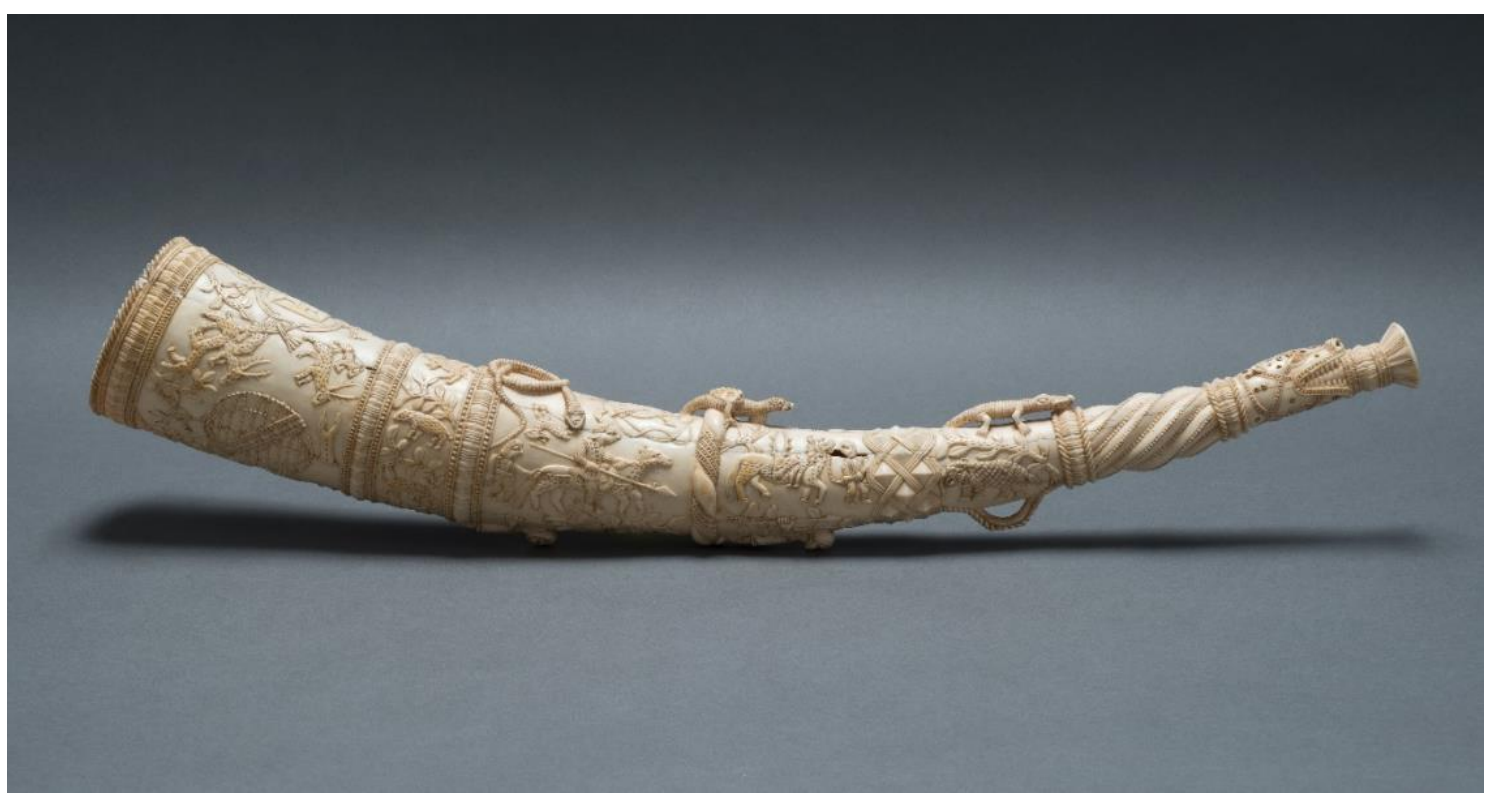

Fig. 2. - Verso de um olifante sapi-português com o brasão de armas do Reino de Portugal. Inícios séc.

XVI. Olifante da caccia. Marfim esculpido em alto e baixo-relevo; $63 \mathrm{~cm}$. MuseiRealidi Torino, ArmeriaReale: Africa Occidentale, Inv. Q. 10. 


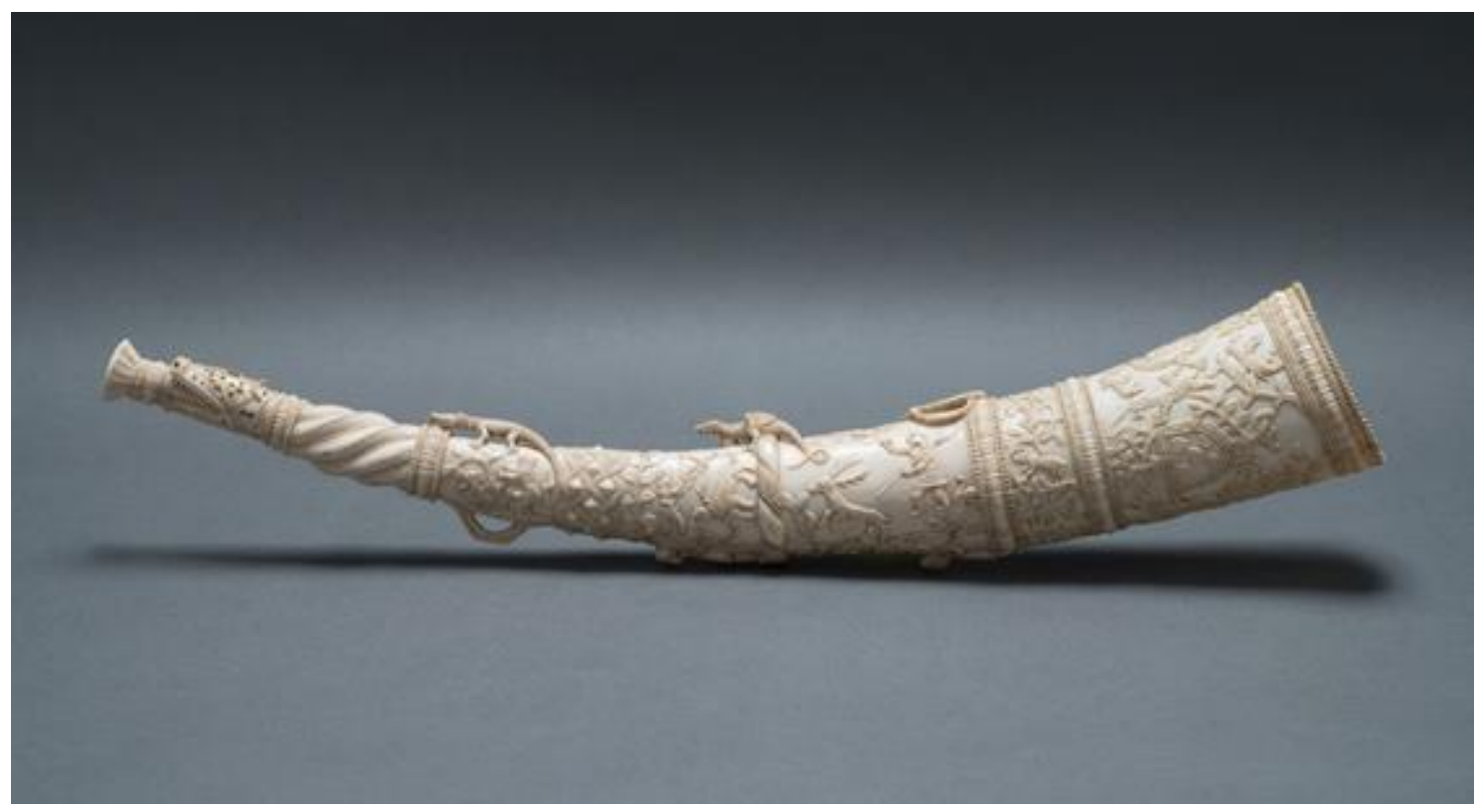

Fig. 3 - Reverso de um olifante sapi-português com o brasão de armas do Reino de Portugal. Inícios do séc. XVI. Olifante da caccia. Marfim esculpido em alto e baixo-relevo; $63 \mathrm{~cm}$.

Musei Reali di Torino, Armeria Reale: Africa Occidentale, Inv. Q.10

\section{Olifantes/ trompas de caça sape-portuguesas}

Os olifantes são trompas de caça, muitas vezes referidas como buzinas e dizem respeito a instrumentos sonoros compostos por um bocal e uma campânula. Eram utilizados para convocar e convidar para banquetes, guerras e audiências.

Nas caçadas da nobreza eram empregues para aturdir as presas e levá-las a saírem dos seus refúgios, mas também para anunciar a sua captura aos restantes membros do grupo.

No entanto, estas peças nem sempre tinha uma utilidade civil. Devemos ponderar o facto de puderem ter uma função estritamente religiosa. Serem utilizados como relicários, por exemplo. Uma hipótese a considerar para as peças que apresentam uma decoração com cenas e inscrições religiosas e expõem a campânula - o bocal por onde saí o som - tapada (Curnow, 1983).

Certamente, na conjuntura africana também seriam instrumentos de guerra, além de intervirem em rituais importantes servindo de exemplo - já para a segunda metade do século XVI o mencionado contexto bélico do uso de trombetas e buzinas de marfim entre os Cassangas na região da atual Casamansa na Serra Leoa. 
Hoje conhecem-se quarenta e dois olifantes apelidados de sape-portugueses. Destes, cinco, dizem respeito a fragmentos convertidos em polvorinhos, nos séculos XVI ou XVII (Bassani, 2000: 149). Esculpidos na forma do próprio dente do elefante, esta tipologia de peça foi valorizada, no contexto europeu, muito antes do contacto estabelecido entre os europeus e os africanos do oeste africano. Temos notícia da chegada dos primeiros olifantes à Europa pelos muçulmanos e os principais centros de produção situavam-se no sul de Itália, na Sicília e em Espanha, mais precisamente em Córdova (Curnow, 1983).

Estas trompas de caça apresentam discrepâncias a nível da qualidade plástica. Uns evidenciam um maior cuidado no talhe, e dizem respeito a peças com aproximadamente $60 \mathrm{~cm}$ de comprimento, salvo exceções de alguns com $70 \mathrm{~cm}$, decorados com heráldica europeia, e por isso considerados como objetos de luxo. Por outro lado, é visível a existência de olifantes com uma qualidade plástica mais débil. Pensamos que estes últimos eram realizados para alimentar um contexto comercial de fluxo mercantil entre Europa e África. Devido à qualidade plástica destas peças, estamos certamente na presença de artefactos de menor qualidade na execução. Também existem olifantes que apresentam dimensões entre os 30 e os $50 \mathrm{~cm}$, e outros com apenas $20 \mathrm{~cm}$ de comprimento. Os últimos são peças incompletas que se apresentam como objetos fragmentados e recuperados como polvorinhos, uma vez que ficaram danificados nas extremidades.

De uma forma geral, estas peças apresentam uma decoração que se desenvolve em várias reservas. As quais, apesar de terem um discurso interligado, apresentam vários momentos da caçada onde se observa uma fauna e flora europeia.

A primeira reserva diz respeito ao bocal, estabelecido por uma ou duas pequenas peças de formato troncónico que entram pelas goelas de um animal estilizado, normalmente a figura de um cão feroz, que surge apenas com a cabeça estilizada e dentes a morder o bocal. A terceira reserva fica intercalada entre duas secções circulares duplas, apresenta uma decoração espiralada com fiadas de perolas que acompanham o movimento já descrito. Apenas na quarta reserva surge a primeira cena cinegética sobre um fundo neutro. Na quinta reserva surge a segunda cena de caça enquadrada em espaços com muita vegetação, de modo a incutir a atmosfera do ambiente florestal em que se desenrolam as cenas de caça. Segue-se uma sexta reserva unicamente ornamental que pela sua largura, constitui-se como uma zona dotada de identidade própria, sendo normalmente ocupada com padrões de entrelaçamento de bandas cordiformes ou encanastradas (Bassani e Fagg, 1988: 97).

A sétima reserva volta a representar uma cena de caça com elementos vegetalistas que é 
dominada normalmente, pela representação de caçadores de lança na mão, alguns tocando olifantes, num curioso jogo de autorreferência, guiando cães de caça que perseguem lebres. É nesta reserva que contemplamos alguns apontamentos heráldicos, como o escudo real português ou a cruz da Ordem de Cristo. Finalmente, na oitava reserva surgem apenas motivos decorativos. É aqui que se pode contemplar a estilização de uma planta de haste longa - que torneia a superfície curva de forma linear. Este enrolamento sugere a delicadeza de um filigranado (Afonso e Horta, 2013: 79-97).

As cenas cinegéticas apresentam uma matriz iconográfica claramente europeia. Presente nos animais que determinam a temática decorativa, na indumentária, na fisionomia dos caçadores e nas armas que usam. Estas cenas apresentam, tal como já foi considerado por anteriores investigadores, uma evidente inspiração em fontes iconográficas de origem europeia, nomeadamente as gravuras dos Livros de Horas (Bassani, 2008:65-69).

Uma dessas fontes diz respeito ao Horae Beatae Mariae Virginis, impresso em Paris no ano de 1498, na tipografia de Philippe Pigouchet para o editor Simon Vostre. Embora a influência do mesmo, sobre os marfins luso-africanos, não seja desconhecida da historiografia (Ezio Bassani já o menciona em 1988) salienta-se a existência de uma tradução de latim para português, realizada no ano de 1503 (Dias, 2010). Aqui reside a explicação para a existência de cenas cinegéticas em peças pedidas por encomendadores portugueses. A existência de uma edição em português terá sido, certamente, a fonte inspiração mais próxima do artesão africano, e como tal lhe serviu de base de trabalho (Bassani, 1998:1-2).

Sousa Viterbo (1845-1910), o primeiro português que se referiu a esta tradução do latim para português (Viterbo, 1901:43-44), sugere que estamos perante uma encomenda que visava a missionação, sendo este um provável exemplar da edição dos cem livros de Horas que o Rei D. Manuel I mandou enviar ao Preste João (Barreto, 1880:55).

\section{Os polvorinhos}

A partir do século XVI as armas de fogo tornaram-se mais sofisticadas, mas continuaram a necessitar de um elevado número de apetrechos para serem manuseadas. Estes recipientes eram transportados pelos caçadores à cintura e acompanhavam as armas de fogo utilizadas pela aristocracia, como observamos esculpido em alguns saleiros ditos do Benim (Fig. 4), sendo utilizados até meados do século XIX (Fadala, 2006:58).

Uma vez que o marfim permite isolar a pólvora da humidade, estes objetos são exemplos da estima que as peças luso-africanas conheceram no âmbito cinegético, bem como no mundo da 


\section{pontěditora}

caça e da montaria áulica no inicio do Período Moderno (D’Anthenaise e Chatener, 2007).

Estes reaproveitamentos mostram-nos a forma e receção destas peças de marfim na Europa após o século XVI. Com efeito, pouco se conhece da história mais remota de muitas das peças luso-africanas, já que as mesmas deixaram de ser mencionadas nos inventários portugueses logo a partir do século XVI (Crespo, 2016: 62 e 63).

Dos fragmentos de olifantes sapes convertidos em polvorinhos, dois dizem respeito ao reaproveitamento da secção final e da secção central de um mesmo olifante, os restantes dizem respeito a pequenas porções que se partiram. O facto de terem chegado até aos nossos dias permitem-nos considerar a utilização destas peças num contexto em que eram facilmente destruídas, como é o caso da caça.

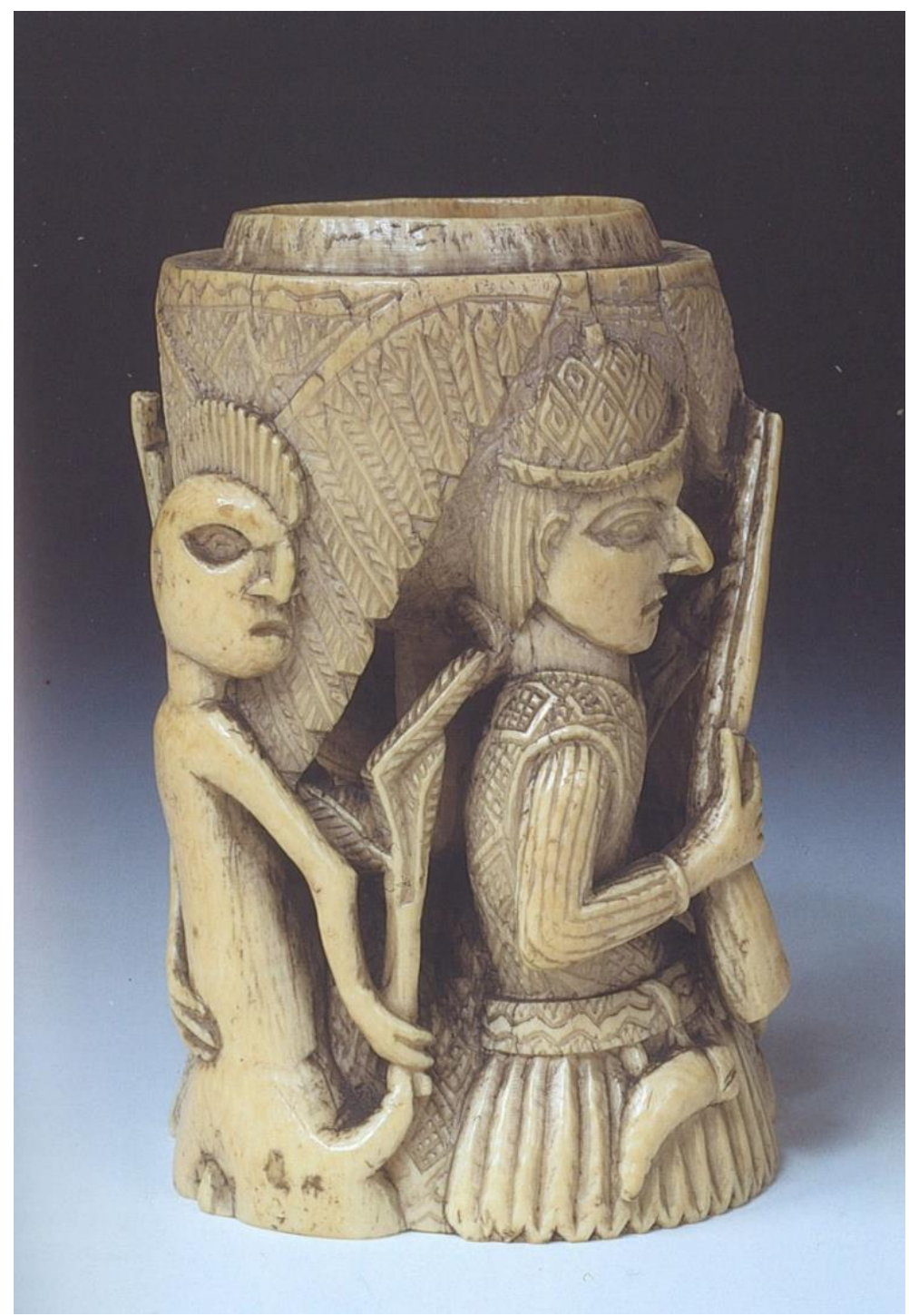

Fig. 4. - Fragmento de um saleiro bini-português. Coleção particular. Lisboa. 


\section{Um polvorinho de marfim com cenas cinegéticas}

A peça em analise diz respeito a um fragmento, de marfim do século XVI, que é rematado por duas anilhas de ferro e diz respeito a um polvorinho (fig. 5 e fig. 6) de $25 \mathrm{~cm}$ de comprimento. Estamos na presença de um dos cinco fragmentos de um olifante convertido em polvorinho. Ao analisar esta reminiscência, denotamos que ela corresponderia à parte central de um olifante sapi-português. O mesmo estaria mais ou menos delimitado por duas argolas de suspensão das quais resta apenas a porção de uma, localizada junto ao orifício em forma de bico, por onde sai a pólvora. Da comparação formal com outros exemplares completos, observa-se que faltam as primeiras três reservas decorativas: o bocal troncónico, a representação da cabeça de um animal estilizado, e uma terceira reserva constituída por uma decoração formada por um conjunto de bandas que se encontram posicionadas na diagonal, intercaladas por linhas perladas. Da peça original apenas sobrevivem a quarta, quinta e parte da sexta reservas. Invariavelmente apresentam cenas cinegéticas onde se contempla um javali fêmea (fig. 5) e no seu reverso um leão heráldico (fig. 6). A quinta reserva é a maior e apresenta a caça à lebre (fig. 5) e no reverso um veado a ser atacado por três cães (fíg. 6). Esta última tem como base a que encontramos nas tarjas do livro de horas em edição portuguesa Horae Beatae Mariae Virginis. No que resta da sexta reserva observamos um friso encordoado que se interceta regularmente a meio. Na parte terminal desta mesma reserva é visível algumas reminiscências heráldicas que não apresentam leitura. A isto acresce a falta da última secção onde estaria a campânula.

O entalhe e as qualidades técnicas e artísticas observadas nesta peça permitem evidenciar a perícia de quem a esculpiu.

Resumindo a análise à reserva central, que corresponderia à quinta antes do olifante se fragmentar, observamos uma cena cinegética de caça a um veado de longas hastes, com o apoio de cães. Mas, simultaneamente também observamos uma caça à lebre. Ao contrário de outros marfins sapi-portugueses, onde este tipo de cena a vários animais surge apenas na sétima reserva, este não apresenta sinais de vegetação. No entanto, não deixa de ser curioso que esta composição cinegética seja semelhante a gravuras europeias, já do século XVII, que evidenciam a caça realizada com cães a veados e lebres, enquanto caçadores de fisionomia europeia erguem as suas lanças. O mesmo se observa nas gravuras de Virgis Solis (15141568) que vêm reproduzidas no volume 19 do Illustrated Bartsch. O detalhe mais relevante 


\section{pontěditora}

desta peça vai para a representação do caçador que traja à europeia e que sopra um olifante com uma decoração simulada em reservas. Esta autorreferencia clarifica a importância que estas peças tinham no contexto da caça europeia e mostra que os artesãos africanos tinham a perfeita consciência de que estavam a realizar peças, que no contexto europeu era valorizado. Em suma, esta montagem seiscentista em ferro demonstra a estima que as peças esculpidas no século XVI por africanos da região da Antiga Serra Leoa, conheceram no âmbito cinegético, no mundo masculino da caça e da montaria áulica nos inícios da época moderna.



Fig.5. - Verso de um polvorinho; Marfim da primeira metade do século XVI em montagem de ferro do século XVII; Serra Leoa; Marfim entalhado e montagens em ferro; 6 x 25 x 4,5 cm; AR|PAB, Lisboa.

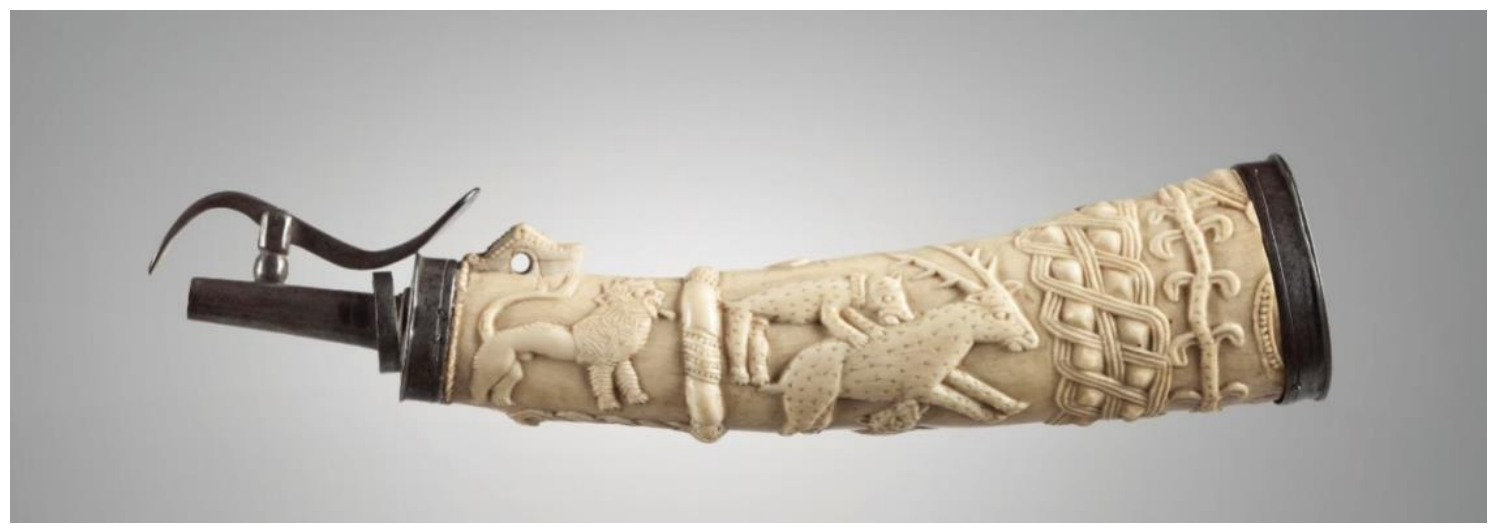

Fig.6. - Reverso de um polvorinho; Marfim da primeira metade do século XVI em montagem de ferro do século XVII; Serra Leoa; Marfim entalhado e montagens em ferro; 6 x 25 x 4,5 cm; AR|PAB, Lisboa. 


\section{Funcionalidades e tipologias de um polvorinho}

As armas de fogo tornaram-se mais sofisticadas a partir do século XVI, mas continuaram a necessitar de apetrechos para serem manuseadas. Um desses utensílios era o polvorinho, que diz respeito a um pequeno recipiente, destinado a guardar a pólvora utilizada para carregar as armas de fogo, antes da invenção dos cartuchos pré-fabricados. Ou seja, a utilização deste instrumento esteve patente até meados do século XIX e os mesmos acompanhavam as armas de fogo utilizadas pela aristocracia. Num curioso fragmento de um saleiro bini-português, é visível a representação de um polvorinho preso na cintura de um europeu que segura uma arma de dois canos (fig. 5).

As fisionomias destes "cantis para pólvora" são as seguintes: em forma de pequenos cornos, configuração em "Y", pera achata, redondos e achatados e por fim em forma de grandes frascos triangulares com recantos côncavos. Estes últimos podendo ser pousados sobre uma superfície plana (Fadala, 2006: 53).

Realizados nas mais diversas matérias-primas como chifres de veados, madeira, cobre e marfim, os mesmos são compostos por duas entradas posicionadas em cada extremidade. $\mathrm{O}$ "fundo amovível" por onde entra a pólvora e o bico injetor, que funciona como um tampão articulado por uma mola, com o qual se atesta a arma de fogo (Fadala, 2006: 58).

As armas e as armaduras raramente estão relacionadas com a arte. No entanto, eles foram influenciados pelas mesmas fontes que a escultura, a arquitetura ou qualquer uma das áreas das artes decorativas, como a ourivesaria e a cerâmica. Assim, devemos contemplar a armaria como objetos artísticos e não só como instrumentos militares. Durante o século XVII, a Europa continuava a valorizar a produção de utensílios em marfim para a caça, e foi nesta altura que os polvorinhos, ricamente decorados com baixos-relevos entalhados, passaram a ser tidos como objetos de arte e não só utilitários. Estes, por sua vez quando destinados para um uso militar - por exemplo para as tropas - apresentavam uma componente decorativa menos elaborada. Juntam-se ainda os mais decorados que eram utilizados nos hobbies da aristocracia, como as caçadas. Objetos caros e símbolo de estatuto social que por isso eram exibidos como verdadeiras peças de ourivesaria e/ou joalharia (Grancsay: 1931:76-77). 


\section{Considerações finais}

Desde os tempos mais remotos, o marfim foi símbolo de poder e do estatuto social, sendo já referido na bíblia onde é associado as riquezas do Rei Salomão (I Reis 10, 18-19). Na Idade Média passou a ser equiparável aos materiais nobres, de proveniência mineral. Nos finais do século XV tornou-se uma das principais materiais primas nos contactos entre europeus e africanos.

Este polvorinho é uma peça singular devido ao reaproveitado de que terá sido alvo, ao transformar-se de um olifante para o seu atual estado. A sua transformação suscita que estas peças produzidas no continente africano foram valorizadas pelos europeus do século XVII. Seguindo o modelo dos realizados na Europa de então, nomeadamente na Alemanha, esta peça é composta por um corpo em forma de corno com dois orifícios - um em cada extremidade - montados em ferro. Um "fundo amovível" e um bico injetor que funciona como um tampão articulado por uma mola, com o qual se atesta a arma de fogo.

O interesse desta peça não se cinge ao facto de ela ser um reaproveitamento. A sua cena cinegética apresenta uma caça mista onde, na mesma reserva decorativa, encontramos a representação de cães a atacar um veado de longas hastes e um caçador a tocar uma trompa de caça, num curioso exemplo de autorreferencia, que anuncia a captura de lebres.

É este detalhe, aliado ao facto de a autorreferencia apresentar um olifante que imita uma decoração em reservas, que torna este polvorinho um curioso objeto sapi-português.

Nas últimas décadas têm-se multiplicado as exposições, os estudos e as publicações sobre a produção artística portuguesa realizada durante a Expansão Portuguesa. 
Notas de rodapé

${ }^{1}$ Este trabalho é financiado por Fundos Nacionais através da FCT - Fundação para a Ciência e a Tecnologia no âmbito do projeto Marfins Africanos no Mundo Atlântico: uma reavaliação dos marfins luso-africanos, PTDC/EPHPAT/1810/2014. 


\section{Referências bibliográficas}

AFONSO, Luís Urbano e HORTA, José da Silva, "Afro-Portuguese Olifants with Hunting Scenes (c. 1490-1540)." Mande Studies, 15, 2013, pp.79-97.

BARRETO, J. A. da Graça, "Presentes de D. Manuel ao Preste João e seu Embaixador" no Boletim de Bibliografia Portuguesa e Revista dos Archivos Nacionais, Dir. Aníbal Fernandes Tomás, 1880 (2), pp. 55;

BASSANI, Ezio e FAGG, W., Africa and the Renaissance - Art in Ivory, New York, Center for African Art, 1988.

BASSANI, Ezio, African Art and Artefact in European Collections 1400-1800, Londres, British-Museum Press, 2000.

_., Ivoiresd'Afrique dans les anciennes collections françaises, Actes du Sud e Musée du Quai Branly, 2008.

_. 'Ivoires Afro-Portugais et livres d'heures imprimés à Paris fin du XV-début du XVI siècles', Nouvelles du livre ancien, 94, 1998, 1-2, - http://nouvelles-du-livreancien.net/article77.html [consult: 20/03/2017].

CRESPO, Hugo Miguel, Choices, Lisboa, AR|PAB, 2016;

CURNOW, Kathy. The Afro-Portuguese Ivories: classification and stylistic analysis of a hybrid art form.[s.1.]:[s.n.], 1983: Dissertação de doutoramento apresentada à Universidade de Indiana, 2vols.

DIAS, João José Alves, Rezar em português: Introdução ao Livro de Horas de Nossa Senhora segundo costume Romano... Paris: Narcisse Brun, 13 de Fevereiro de 1500 [i.é 1501], Lisboa: Biblioteca Nacional de Portugal, 2009; 2. a ed., 2010;

FADALA, Sam, The Complete Black powder Handbook, Iola, Krause Publications, 2006,

FAGG, William, Afro-Portuguese Ivories, London: Batchworth Press, 1959.

FERNANDES, Valentim. Códice Valentim Fernandes. (Leitura paleográfica, notas e índice de José Pereira da Costa). Lisboa: Academia Portuguesa da História, 1997. 
GRANCSAY, Stephen V. "A Silver-Mounted Powder Horn." The Metropolitan Museum of Art Bulletin 26, no. 3 (1931).

HENDRIE, Robert (ed.), Theophilus, De diversisartibus: seu Diversaru martium schedula, John Murray, Londres, 1847;

MARK Peter, Towards a reassessment of the dating and geographical origins of the LusoAfrican ivories, fifteenth to seventeenth centuries, in History in Africa. 34, 2007.

MARK, Peter. "Towards a reassessment of the dating and geographical origins of the LusoAfrican ivories, fifteenth to seventeenth centuries". History in Africa. 34 (2007), p. 189-211.

MARTINEZ, Eugenia Soledad, Crossing cultures: Afro-portuguese ivories of fifteenth - and sixteenth century Sierra Leone, Uma tese apresentada na pós-graduação da Universidade da Flórida em cumprimento parcial com os requisitos para a obtenção do grau de mestre em artes, Universidade da Flórida, 2007.

MASSING, Jean Michel, "Os marfins africanos e os portugueses" in AA.VV., Marfins no Império Português/Ivories in the Portugueses Empire, Scribe, Lisboa, 2013).

VITERBO, Sousa, A livraria Real especialmente no reinado de D. Manuel. Memória apresentada à Academia Real das Sciencias de Lisboa. Lisboa: [Academia das Ciências9, 1901. (Sep. De História e Memórias da Academia Real das Sciencias de Lisboa, Nova série, Classe de Sciências Morais, t. 9, pt.1); 